\title{
REHABILITATION AND FUNCTIONALITY OF ARCHITECTURAL MONUMENTS TO PRESERVE THEM FROM DAMAGE FACTORS \\ Hatem Tawfiq AHMED *
}

Department of Architectural Sculpture and Formation, Faculty of Applied Arts, Helwan University, Egypt

\begin{abstract}
The process of maintenance and rehabilitation of archaeological buildings play an important and vital role in preserving the human heritage from exhaustion to remain an essential and indispensable milestone through its interaction with the community in addition to the economic aspect gained from its reinvestment. Developed countries have known that, the best way to preserve the historic building and prolonging its life alongside maintenance, is by its rehabilitation by providing a new function that ensures its survival and continuity, with taking in the consideration that no damage occurs to its historical value and privacy and that the new function be harmony consistent with the cultural nature of the architectural building and its structure and the rehiring of buildings and consist with the conditions of venice agreement 1964.

Keywords

Rehabilitation, Functionality, Architectural Monuments, Preserve, Damage Factors.
\end{abstract}

\section{Introduction}

The re-employment of archaeological buildings and areas are considered the best solutions that balance between the needs of urban growth, and estate development and economic benefit, therefore the process of rehiring is important for both the building itself or for the urban environment and the general nature of the city it contains. Rehabilitation and functionality of buildings and archaeological areas are to preserve them from damage is what must be the top priority of governments, archaeological and tourist organizations The research discusses the problems associated with the damage caused by leaving the buildings without rehabilitation and usage, and the possibility of developing an effective strategy for the rehabilitation and employment of architectural monuments that harmony with contemporary reality and try to meet future challenges in protecting them from natural and human damage.

\section{Research problem :}

The study The lack of research interest and the failure to make maximum use of research studies dealing with the rehabilitation and employment of architectural monuments and their preservation from the factors of damage, despite everyone's agreement on the importance of preserving and protecting them from extinction.

\section{Preserving the architectural heritage:}

Preservation operations that take place on archaeological buildings or areas of value and on all the buildings of interest, specific installations, a distinct urban environment, or a unique urban

* Corresponding author: appliedarts@a-arts.helwan.edu.eg 
fabric, which is an action taken to prevent the deterioration and distortion of historical cities or heritage buildings and includes all works that work to extend the life of the heritage And the distinctive civilized character of those cities and buildings. It is the maintenance of archaeological buildings and taking care of them to perform their function for which they were found with high efficiency, and to preserve their material value despite the end of their life span, which is those measures that are taken to prevent corrosion and extend the life span of archaeological buildings.

\section{Objectives of employment and reuse:}

1- Raising the aesthetic value of the archaeological building and the existence of a framework of communication between it and the surrounding environment.

2- Creating a kind of permanent supervision over archaeological buildings by means of their users and specialists in a way that will prevent them from being neglected and abandoned, as well as preventing their direct encroachment and destruction.

3- Protection, preservation and revival of ancient buildings and ensuring the continuity of maintenance work for them, especially short-term works such as cleaning work, whose continuity is difficult to ensure without re-employing the building.

4- Community participation in the proposed function and the introduction of the building into the organic entity of the site, or the heritage area to which it belongs.

5- Providing the heritage domains of the old deteriorating neighborhoods with the necessary services without the need to construct new buildings:

6- Reviving the social and cultural values and the components of the cultural heritage that have disappeared so that the building becomes an effective and interactive part with the community.

7- Development of the community surrounding the ancient buildings, which helps preserve the distinctive urban character of the historic area.

8- Preserving the historical scenes that cannot be replaced and improving the physical environment of heritage areas and buildings, as their re-employment contributes fundamentally to improving their physical environment.

9- Proper use of traditional areas while preserving their historical character and character, preserves for the city its heritage and memory, as well as the memory of its peoples from melting away in an era in which cultural legacies at the global level diminish and identity lost. 10- Attracting and attracting tourists from different parts of the world to get acquainted with a different and distinct culture, thought and civilized heritage through which people get to know each other.

11- Providing the structural safety of the archaeological building, through structural studies 
that precede re-use, and regular maintenance will be a protective indicator to avoid any effects on the archaeological building from a structural point of view.

12- Creating a kind of public sympathy between the archaeological building and its users and its beneficiaries through the new function that the building performs for the surrounding community, which works to interfere with the building with the surrounding environment in the form of cultural and educational services, and helps to improve and raise the standard of the living environment.

13- Increasing the archaeological awareness of the inhabitants of the area surrounding the historical buildings and considering them a cultural heritage that must be preserved and adhere to staying in it and thus revive the historical area.

14 - Maximizing the benefit from the historical heritage and adapting its use, present and future, to contribute to the revitalization of society in thought, culture and art.

15- Re-employing historical and archaeological buildings works to provide an adequate return that covers the needs of these buildings, despite the fact that the building's economic goal is considered partial and not one of the main goals of employing the building.

16- Communicating the cultural, humanitarian and artistic message contained in the archaeological building to the new generations in a clear way, by living with the valuable building for the current era and playing a positive role in society.

17- Completing the system of preserving archaeological buildings to make them a tourist attraction, to be placed on the cultural and tourism map to maximize the preventive preservation role of these buildings.

Criteria for re-employment of archaeological buildings The process of adopting a new type of use for historic Minni includes a set of criteria that contribute efficiently to determining the type of best use for such buildings, which requires not adversely affecting the architectural and heritage value, as well as ensuring the continuity of its performance and its functional life for the longest possible period as follows: :

1- That the new job is consistent with the architectural character of the city and preserving its identity, so that it is compatible with the area and location of the building, provided that it does not affect: the modifications added negatively to the building in terms of construction or aesthetics.

2- The choice of the new job for the building should be based on the social, cultural or economic return that this job represents, so that the archaeological building becomes a product of financial resources and the continuity of maintenance work that ensures the sustainability of conservation operations. 
3- That the new job does not entail any modifications to the building's planning, with the exception of the necessary supplies, and that it is not distorting the building and its technical elements, and its introduction does not entail any dangers that harm the building.

4- When choosing the function of the antique building, it must be taken into account that it does not result in the permanent presence of a large number of the public and the consequences of tampering with the building's elements.

5- The designer must choose the most appropriate furniture styles needed for the use so that they appear derived from the technical features of the foundations in the building or existing in the same era in which it was built.

6- When choosing its new position, the archaeological building should be related to the size of the return on the site of the city's antiquity, that is, the more popular the function, the closer the chosen archaeological buildings are to the main streets.

7- The job must be chosen in relation to the building's area, voids and location, so that the proposed job does not need to make any addition to the building, that is, the perfect match between the spatial building requirements and the job requirements and their consequences.

8- The possibility of self-financing the building through new use, current and future market requirements, and expected financial results in the future.

9- Not to repeat the job at close distances, and that the job's activity does not have a negative impact in the form of pollutants, or water leakage, and it is not allowed to convert any mosque to any other use.

10- Adequacy of the new function of the heritage environment and the architectural nature of the building in a way that preserves the building's heritage character and increases people's awareness of the architectural heritage

Criteria for selecting historical buildings for their rehabilitation and employment

. The age of the building, the time of its construction and the historical stage it represents: the greater the age of the building, the greater its historical value and the linkage of the heritage building with events

A distinctive national, historical or social situation that makes the process of preserving and rehabilitating it an imperative. The homogeneity of the site and its importance: the existence of a mutual influence between the historical building and its site, so preserving a historical building has a great role in the revival of buildings

It is adjacent to it, and increases its architectural value 3- The social dimension: the archaeological building's association with social or cultural events. People have a role in history and society, such as writers, politicians, and scholars 
And others make the heritage building an event that narrates the creations and glories of those personalities who lived in it. (Al-Maliki, 2008 AD) 4- The political value Some buildings prove a certain identity or idea and through preservation it is possible to learn from the past, narrate history and express the situation

The political dominating those buildings e. Architectural and aesthetic value: style, character, shape, formation, juxtaposition, function, specific form, method of creation, expression ... etc. As some archaeological buildings represent an unconventional architectural style that has distinct design details and treatments that increase its aesthetic and architectural value. 6 . Religious value: Some heritage buildings have a religious value according to the culture associated with them and according to the ideological strength of the community. $\vee$. Tourism value Some buildings or archaeological sites have an evident value in stimulating tourism, as local and international tourism is one of the most important tools of exchange The cultural and the possibility of re-using the rehabilitated buildings as cultural shrines or museums, which provide visitors with the experience of understanding the heritage and culture of the community. The uniqueness of buildings in their architecture with the presence or absence of one of the important characteristics of buildings that distinguish them from similar ones in the time of its existence or in the past

Where the content form - signed use ... etc), or it may represent the only remaining model that embodies a particular style. (Mofleh 2009 AD) 9- Economic value: the role of the archaeological building in the tourism and commercial movement, handicraft production, light industries ... etc. There must be a benefit

Economic for the area to be preserved so that it is not a negative result of preservation and an economic burden on the one who is in it 10 - The planning value: the link with the homogeneous planning sectors, the economic and social role, and the relationship of the building with the rest of the components of the region

History, shape of the area, movement system, services ... etc). 11 - Functional competence: It is imperative to exceed a certain limit of the functional competency of the heritage building within the general functional structure of the area in its texture. 12- Providing service supplies, especially health services and other services required by the times, and this is also related to the function associated with the buildings.

Or squares after preservation, and also includes studying the introduction of services without negatively affecting the value of the historical, architectural and aesthetic heritage 12- The availability of information and documents that make the preservation an accurate process without obstacles and the possibility of conducting it without a negative impact on the historical 
value of the building. 14- Harmony of the architectural heritage and contemporary man: the existence of a minimum level of compatibility between the human element and the heritage building that qualifies it for life in this era.

And compliance with its requirements (HE 2009)

\section{Obstacles facing the rehabilitation and employment of heritage buildings:}

1. The continuous deterioration of the built environment in which the impact is located and the demolition of many archaeological buildings with the aim of development and investment and thus dismantling the urban fabric representing the culture of nations

2. The random and ill-considered restoration of the archaeological buildings by their owners or investors, and the absence of basic rules for the restoration. The absence of an inventory of buildings and heritage areas, socio-economic development

3. The absence of awareness of the importance of the architectural heritage and the lack of funding necessary to achieve the conservation process.

4. The relationship between heritage and tourism sites is a dynamic one and conflicts of values may occur.

5. The lack of a comprehensive planning study or an integrated plan, especially for the reuse of archaeological and historical buildings.

6. The absence of legal protection and the failure to establish mechanisms that contribute to increasing the participation of civil society institutions in the rehabilitation and employment process.

7. The length of the implementation period and the increase in the cost than expected due to the continuous rise in the prices of materials, the diminishing financial capacity, the lack of trained technicians ... etc.

8. The lack of clear controls in choosing the type of new employment and the nonparticipation of citizens in choosing it due to the absence of awareness among the public of the importance of buildings This leads to their lack of sympathy with those jobs, their lack of participation, and their diminished interaction towards the development, operation and maintenance of historical buildings.

9. The introduction of some modern electromechanical systems, as the archaeological buildings were constructed at a time when these systems did not exist, and therefore the existence of such systems was not subject to the designer's calculations, in addition to the absence of continuous technical monitoring of the re-employed antique buildings.

10. Additions may include And the modifications required by the proposed use, architectural treatments, security techniques, and technical equipment, which may not 
be commensurate with the investor's capital, when there are fewer service elements and activities that attract the public.

11. High cost of reuse operations, to increase the economic cost of maintenance, restoration and preservation operations, which It depends primarily on the structural condition of the building, the rates of damage and its types, and their impact on the efficiency of the performance of the new use.

12. The low economic return of the new use, which may not be commensurate with the investor's capital, when the service elements and activities that attract the public are reduced and provide the necessary return for spending.

13. Weakness and knowledge of technical control while carrying out re-use and rehabilitation of the building, which sometimes leads to additions that may harm the building.

14. The tendency of plans to preserve historical buildings to link them to the surroundings in which they are located adds to the executive bodies a consumption of financial resources, for maintenance and restoration work And also to manage and take care of the urban surroundings

\section{Results:}

1- The wrong choice of the type of new employment for ancient buildings damages its architectural value and accelerates its level of deterioration.

2- Re-employing the architectural heritage as a means to revive the traditional professions and crafts, as they arise in the invested heritage site or in its vicinity with small workshops and factories.

3- The lack of information related to the archaeological buildings and the lack of an integrated database about them and the information that this includes about their sites, their history, and the engineering documentation for them. On them to keep buildings.

4- Re-employment is the most important strategy for methods of preserving the architectural and urban heritage of the ancient Arab city, and thus preserving the cultural identity of these cities to ensure their continuity and preservation for future generations.

5- Re-employing the architectural heritage helps to enhance the cultural dimension in society by affirming pride in the values of the past, a sense of belonging and identity.

6- Re-employing the architectural heritage contributes to the protection of cultural and historical properties, contributes to a sense of belonging and achieves sustainable development. 7- Giving equal importance to the archaeological building and the surrounding area through legislation helps to fully preserve the architectural heritage areas. 
8- Re-employing heritage buildings for purposes that serve the community and provide a direct benefit to it, leading to community interest in preservation and upgrading projects.

9- Re-employment of buildings and archaeological areas. Adequate employment not only helps to develop and restore life to them, but also affects neighboring urban entities and extends its impact to other areas.

10- Giving equal importance to the ancient buildings and the surrounding area helps to fully preserve them. The best way to preserve ancient buildings is to rehabilitate them and use them in a new job that will ensure their survival.

11- Taking care of the needs of the present at the expense of the human heritage is one of the grave mistakes that humanity has committed in many eras.

12- The analysis of successful experiences leads to the development of preserving the architectural heritage and the transfer of expertise to successive generations. The development of antique buildings and their re-employment requires changing the idea of converting these buildings into museums or cultural palaces.

13- Developing the means and techniques for preserving heritage buildings to reduce the chances of these buildings being affected by natural phenomena such as earthquakes.

14- The policies followed in the field of preserving the architectural heritage in different countries reflect a true picture of the economic, political and social conditions in these countries.

15- The archaeological buildings represent a major source of national income and a source of tourist attractions, as they are considered a heritage.

16- The policies of preserving the architectural heritage of maintenance, restoration, reemployment, reshaping, revival and renewal of heritage lead to achieving aesthetic, environmental and economic benefits in heritage buildings, employing archaeological buildings for tourism purposes as artistic and cultural centers that contribute to the development of cultural and artistic life and support tourism with the appropriate employment of buildings Archeology leads to many planning and organizational procedures in the surrounding areas and helps to set new rules for construction and architecture in them.

17- Preserving the architectural heritage includes all the preservation processes that take place for archaeological buildings and areas of archaeological value and for all the buildings they contain of interest, a distinctive urban environment, or a unique urban fabric. The effective role of the media in the visitor turnout for the re-employed archaeological buildings, in addition to its role in the tourism promotion of the neighboring region.

18- The acute shortage of government financial resources in addition to natural, human, social, 
cultural, constructional and administrative factors, which directly affected the loss of heritage buildings at the global level and neglecting their maintenance and restoration.

19- Lack of legislation and regulatory frameworks related to the process of re-employment, investment and development of archaeological buildings, weak legal frameworks related to the protection of architectural heritage, and problems of ownership of historical buildings. Distinguished architecture in all ages can coexist with each other despite the difference in style, size and building materials used in the restoration and rehabilitation Heritage buildings by reemploying them play an important role in the process of economic and social development and contribute to the urbanization movement at the level of the region and the city.

20- The human element plays a major role in the destruction of archaeological properties as a result of the low level of awareness of the importance of heritage, the concepts of sustainability, and the weakness of human and institutional capabilities related to the development of heritage buildings.

21- Heritage buildings need help from governments because they are not fully exploited and misused, and suffer from informal encroachments and neglect despite the provision of capabilities, especially in the field of tourism.

22- Weak public awareness of the importance of the architectural heritage and the cultural value it represents is one of the main reasons for the lack of restoration and architectural preservation and thus the increase in the dangers that threaten it.

23- The limited contribution of archaeological buildings to architectural development due to lack of awareness of the possibilities and ways of investing in it. The existence of socio-urban problems related to the loss of public sympathy with heritage buildings and preservation projects.

24- Awareness of the basics of classifying heritage buildings and the existence of documentation and registration of them that achieves a balance between the value of these buildings and the process of their rehabilitation and employment.

25- The outlook on architectural heritage has developed at the international level in the form of treaties and charters sponsored by international organizations, as well as local interest in the form of legislations and laws to preserve the architectural heritage, although there are some shortcomings. Ancient buildings have been repurposed as museums and galleries, and not all areas have been properly employed.

\section{Recommendations:}

1- Establishing a database that includes all historical buildings and classifying them in terms of their historical, architectural and social value, provided that this information is available to 
everyone who wants to study the architectural heritage.

2- Establishing a higher advisory body that includes university professors, experts in archeology and restoration, and architects to study the jobs proposed to be occupied in archaeological buildings, make an evaluation of these jobs, determine the nature and needs of these buildings, and the steps necessary to preserve them. The new function of the ancient buildings is similar to their architectural composition, and the employment does not cause any structural defect in them through any modifications to them.

3- Including heritage in school and university curricula and directing scientific research efforts towards topics that serve the re-employment and rehabilitation of architectural heritage.

4- Cooperating with international organizations in the field of providing global expertise to benefit from and study their successful experiences in order to increase awareness and understand the correct methods of dealing with the archaeological buildings that are required to be re-employed.

5- Choosing a permanent job for the building throughout the year, provided that this job serves the tourists and the people of the region and provides them with the services they need, limiting the museum's employment of residential buildings, and allocating them to cultural functions that reflect the family's lifestyle.

6- Educating the private sector about the importance of participating in preserving the architectural heritage and re-employing it, and making this among its priorities in the field of social responsibility and creating smart incentives aimed at attracting investment in the field of rehabilitation and employment of the architectural heritage. Its infrastructure and linking its future use with its environmental and architectural surroundings.

7- Supporting educational institutions in the field of preserving heritage buildings and reemploying them, and launching competitions between universities and antiquities conservation centers regarding practical proposals and feasibility studies for the possibility of rehabilitating and employing archaeological buildings of value. Issuing strict laws by international bodies and organizations to preserve archaeological property and providing awareness, training and educational programs. Increase awareness of the architectural heritage and its importance to various segments of society.

\section{References}

1- Ibrahim, Shaima Hassan Zaki (2008 AD). Re-employment of historical palaces in Egypt, as an application to the palaces of Mohd Ali's family. A magister message that is not published. Department of Architectural Engineering, Faculty of Engineering, Cairo University, Egypt.

2- Ibrahim, Abd Al-Baqi. (18 m). Employment of buildings and archaeological sites. The 
global symposium for the protection of ancient Aleppo. 21/6.

3- Ibrahim, Attia Ahmed, and Al Kafafi Abdel Hamid. (2008 AD). Protection and maintenance of archaeological heritage. Cairo. The Arab Republic of Egypt: Dar Al-Fajr for Publishing and Distribution. I 1.

4- Abu Al-Fadl, Heba Allah Farouk (. 12 AD). Old buildings repurposed. Unpublished MA Thesis, Department of Architecture, Faculty of Fine Arts, Alexandria University, Egypt.

5- Abu Hantash, Nahi Ahmad Hussein. (2008 AD). Towards a Policy for the Rehabilitation of Residential Buildings in Palestinian City Centers, "Case Study Nablus", an unpublished master's thesis in Architecture, Faculty of Graduate Studies, An-Najah National University, Nablus, Palestine.

6- Ahmed, Asamer Zakaria. (2008 AD). Technical criteria for re-employment of buildings as museums according to the concept of value (computer application). Unpublished $\mathrm{PhD}$ thesis. Department of Architecture . Faculty of Engineering, Cairo University, Egypt.

7- Al-Adhami, Marina. (2001 AD). Contribution to an analytical study of re-employment of large residential homes in the old city of Damascus. Unpublished $\mathrm{PhD}$ thesis in Architecture, Damascus University, Syria.

8- Amin, Ahmed. (2012 AD). Al-Sennari House, Bibliotheca Alexandrina. Sennari House Publications Series.

9- Goshawk. Mounir Abdel Qader Mohamed. (2008 AD). Dealing with Interior Architecture Elements in Building Repurposing Projects of Value Unpublished MA. Faculty of Engineering, Cairo University - Egypt.

10- Barakat, Shadia Muhammad, Nazmi, Naamat Muhammad (January 2012). Sustainable design of green architecture between past and present: Case study of Al-Suhaimi House in Historic Cairo and a villa in Al-Nada neighborhood in Sheikh Zayed City - The 1st Insertional Engineering Conference Hosting Major Integrational Innovation. Creativity \& Impact Assessment. Cairo. Egypt. 15-18.

11- Al-Banna, Mr. Mahmoud, Helmy, Fatima Muhammad, Al-Barambali, Hussam Al-Din, Abd Al-Dayem, Alia Abdulaziz (2000 AD). Re-use of archaeological buildings "A study of data and evaluation of alternatives", applied to Saray al-Musafir Khan, in Cairo - Journal of the Faculty of Arts in Qena. The tenth issue.

12- Bukhash, Rashad. (2004 AD). Architectural preservation methodology hypotheses and solutions theses. The first international conference and exhibition Architectural Conservation between theory and practice. Dubai.

13- Hamid, Aya Walid. (2012) M. Sabil Muhammad Ali Pasha, "The Unknown Museum." 
Cairo Antiquities Gate June 16

http://cairohistoric.blogspot.com/2017/04/blog-post.html

14- Al-Halabi, Kamal, Al-Wattar, Dr. (2008). Sustainable development is an approach to preserving the built environment. Conference on Initiatives and Developmental Innovation in the Arab City, Jordan.

15- Al-Hanish, Jamila Al-Hadi, Al-Rumaih, Reda Al-Sadiq. (2012 AD). Reuse of the historic and archaeological building (of value) as an entry point for its preservation. International Journal of Science and Technology Issue (). January.

16- Khalil, Mervat Mamoun. (2008 AD). Tourism Development in Urban Heritage Sites (Challenges and Obstacles: The City of Karak: Case Study :) A working paper presented to the Symposium on National Urban Heritage and Ways of Preserving and Developing it in Tourism, Riyadh. The Kingdom of Saudi Arabia Sept 30 - Oct 30.

17- Dardir, Ihsan Zaky. (18 m). Possibilities of employing archaeological and historical buildings to play the role of museums .. The second scientific conference of the College of Fine Arts. Helwan University .

18- Dahna, Abdul Hamid. (2012 AD). The foundations and controls of the process of rehabilitating historical buildings in the old city of Aleppo. Unpublished MA Thesis - Faculty of Architecture, University of Aleppo, Syria.

19- Zain Al-Abidin, Mahmoud. (2010 AD) evaluating the experience of rehabilitating some historical Ottoman buildings in Syria with cultural functions, the status of museum employment, a comparative study of an unpublished master's thesis at the Faculty of Architecture, University of Aleppo, Syria. Sameh, Kamal Al-Din. (181 AD). Islamic architecture in Egypt, Cairo: The Egyptian General Book Authority, 4th ed.

20- Saadeh, Ayman Azmy Gibran. (2008 AD). Mechanisms for Activating Public Participation in Architectural and Urban Preservation Projects (Case Study, West Bank. Unpublished Master Thesis in Architecture, Faculty of Graduate Studies, An-Najah National University, Nablus, Palestine.

21- Mr. Ahmed Abdel-Wahhab. (181 AD). Maintenance and reuse of archaeological and valuable buildings: Freedom House for Press, Printing and Publishing.

22- Abdul-Baqi Mahmoud. (2012 AD) 12 conditions for re-employment of buildings and archaeological sites, Monday, 15 October

https://www.vetogate.com/3330781

23- Abd al-Qawi, Ahmad. (2012 AD), Aisha Fahmy Arts Complex. 17 / May 2767197 / https: / / www. elbalad. news 
24- Abdullah, hostile to Ghalib Ali. (181) M. A guide to preparing projects for the maintenance and restoration of monuments. Cairo: The Egyptian Antiquities Authority.

25- Abd al-Warith, Amal Abd al-Warith Shad. (2008 AD). Preservation of historical buildings and ways to employ them in the Egyptian city (examples from Cairo). Unpublished master's thesis in the Department of Architecture. Faculty of Engineering, Assiut University, Egypt. 26- Abdel Dayem, Alia Abdulaziz Mahmoud. (2001 AD). Study of the restoration and maintenance of ancient houses in Cairo and their re-employment in application to Sarayat alMusafir Khanna (Ottoman Era) Unpublished Master's thesis. Faculty of Archeology, Cairo University, Egypt.

27- Atma, Muhammad Allam Fawzi (2008 AD). Rehabilitation of Historic Buildings in Palestine "A Case Study in the City of Nablus Since 1994". Unpublished Master Thesis in Architecture, Faculty of Graduate Studies, An-Najah National University, Nablus, Palestine. 28- Uthman, Sarah Ahmed Hamad (2009AD). Reuse of valuable buildings experiences in the Arab Republic of Egypt (documentation and analysis). A magister message that is not published . Department of Architecture . Faculty of Engineering, Cairo University, Egypt. 29 - Askar, Farouk. (September 2008). Cairo City Guide Part II. Research project submitted to the Golden Network Abu Dhabi website.

30- Afifi, Hakim. (1984 AD). Re-use of Islamic antiquities in Cairo, Architectural Journal, Issue (5).

31- Akoush, Mahmoud. (18 m). History and description of the Tulunid Mosque. Cairo: The Egyptian House of Books Press, 1st Edition.

32- Ali, Alaa Jamal. (2012 AD). Mahmoud evaluated alternatives in relation to data on re-use of archaeological buildings, an evaluative scientific study of restoration and maintenance applied to an ancient building in Cairo. Unpublished MA Thesis, Faculty of Archeology, Cairo University, Egypt.

33- Fikri, Ahmed. (2008 AD). Cairo's mosques and schools. Part One - The Fatimid Era. Cairo: Dar Al-Ma'aref i.

34- Al-Kafafi, Abdul-Hamid. (2012 AD). Rehabilitation and employment of archaeological buildings for purposes appropriate to the site of the Guardians of Civilization. -historic-buildings.htmlhttps: //www.civgrds.com/rehabilitation-and-employment-of 35- Al-Majidi, Basem Hasan Hashem Al-Taie, Harith Khalif. (2012 AD). The sustainable preventive preservation of historic buildings. Iraqi Journal of Architecture. Issue (4) December. 36- Al-Maliki, the Faris tribe. (2004 AD) Urban and Architectural Heritage in the Arab World. Amman: Warraq Publishing and Distribution. I 1. 
37- Mubarak, Ali. (18 m). The New Conciliatory Plans for Egypt, Cairo, and its Old Cities and Countries, famous for Bulaq: The Great Emiri Press

38- Mahmoud, Had Fikry and others. (December 2004). Organizing the roles of participants in projects for the preservation of buildings and archaeological areas International Conference. Luxor heritage cities, Egypt.

39- Mohiuddin, Ismail and Abu Ghazaleh, Asaad Ali Suleiman. (December 2010). GIS technology as an effective tool for preserving and developing historical and valuable areas (a case study in the city of Cairo). The eleventh Al-Azhar International Engineering Conference $31-7$.

40- Madbouly, Mustafa Kamal. (18 AD) Rehabilitation of central areas of historical value in developing countries (Cairo case study, Al-Darb Al-Ahmar region). A magister message that is not published. Cairo University . Egypt.

41- The Egyptian, Majd Najdi Naji. (2010 AD). Assessment of restoration methods and techniques in Palestine, Nablus, a case study. Unpublished MA Thesis in Architecture, Graduate School of Studies. An-Najah National University Nablus - Palestine.

42- Mofleh, Nahed Jamil Jabr. (2008 AD). Revitalization and Restoration of the Old City in Awarta Village Unpublished Master Thesis in Architecture, Faculty of Graduate Studies, AnNajah National University, Nablus, Palestine.

43- Al-Maqrizi, Taqi al-Din Ahmad bin Ali. Investigation Zainhum, Mohamed, Sharkawi, Madiha. (18 A.D.): Al-Maqriqat al-Maqriziyya, Part Two: Madbouly Library, 1st Edition.

44- Nadim, Asaad (. 12 AD). Traditional arts and crafts from Cairo. External cultural relations sector. Ministry of Culture .

45- Al-Namrah, Nader Jawad. (2014 AD). A proposed approach to rehabilitate valuable archaeological buildings in Gaza City (an analytical study for the rehabilitation of the ancient Hammam Al-Samra building in Gaza City, in a case study). Al-Qadisiyah Journal of Engineering Sciences. Vol $\vee$.

46- Nur al-Din, Muhammad Imad. (2011 AD). Restoration of heritage buildings, reuse and use of them as an entrance to preserve them. Research and heritage. Studies in Arab heritage. The first national urban heritage forum. The Supreme Commission for Tourism Jeddah, November. 47- Yusef Mohammed Mahmoud Abdullah. (2014). Investment programs in urban heritage and means of financing based on Arab and international experiences. Journal of Urban Research. College of Regional and Urban Planning, Cairo University. The number (12). April. 48- Ahmed, H., \& Ireneusz, P. (2000). Conservation and Reconstruction of Mascaron. The International Conference on Conservation. Kraków. 
49- Nevin Saad Al-Din Abdel Rahman SALEM, INNOVATIVE TECHNOLOGICAL METHODS AND TECHNIQUES TO REVIVE THE ANCIENT EGYPTIAN GLASSMAKING HERITAGE, International Journal of Multidisciplinary Studies in Heritage Research, Vol. 1, No. 2, 2018, pp. 32-38.

50- Zainab Muhammad Munir Abdul-Gawad AL-SEBAEI, EMPLOYING THE AESTHETIC VALUES OF HERITAGE DESIGNS IN KINGDOM OF SAUDI ARABIA TO PRODUCE WOMEN VEST, International Journal of Multidisciplinary Studies in Heritage Research, Vol. 1, No. 1, 2018, pp. 25-31.

Received: January 16, 2019

Accepted: March 28, 2019 